\title{
Ethical global citizenship education: From neoliberalism to a values-based pedagogy
}

\author{
Emiliano Bosio $^{1} \cdot$ Hans Schattle ${ }^{2}$
}

\begin{abstract}
This article proposes an ethical global citizenship education (GCE) framework by offering the following five dimensions: values-creation, identity progression, collective involvement, glocal disposition, and an intergenerational mindset. Ethical GCE draws on a multiplicity of critical literatures to identify characteristics of each of these dimensions. It goes beyond neoliberal/market-driven principles toward ethical perspectives promoting social responsibility, justice, human rights, and glocal sustainability. With further theoretical development and strategies toward implementation, the framework has the potential to be deployed in future research and evaluation of the complex teaching and learning processes involved in GCE, particularly in a values-based perspective.
\end{abstract}

Keywords Ethical global citizenship education - Values-creation · Identity progression · Collective involvement · Glocal disposition · Intergenerational mindset

The effects of an ever-increasingly interconnected and globalized world resonate across a multitude of aspects facing human civilization, including global crises (e.g., the Covid-19 pandemic) that humanity must meet with knowledge and wisdom. The world economy is fueled by rapid technological innovation and the instantaneous flow of information, yet the dividends of this economic activity are increasingly concentrated in the hands of a few (Giroux \& Bosio, 2021). New technologies continue to change the world, yet our reliance on antiquated energy production destabilizes Earth's climate. Any one of these factors

Emiliano Bosio

bosio@toyo.jp

Hans Schattle

hschattle@yonsei.ac.kr

1 Department of English and American Literature, Faculty of Letters, Toyo University, 5

Chome-28-20 Hakusan, Bunkyo City, Tokyo 112-0001, Japan

2 Department of Political Science and International Studies, Yonsei University, 50 Yonsei-ro, Seodaemun-gu, Seoul 03722, Republic of Korea 
would be enough to lead to a fundamental change in human society. Seen as a whole, they signal the possible start of a new era. These issues demand a local to global/global to local approach to education, insofar as the next generation will be able, collectively, to guide human civilization toward prosperity, health, and security.

The notion of global citizenship education (GCE) is one form in which the field of education can confront these issues. In particular, as Wintersteiner et al. (2015) argued,

[GCE] responds to globalization by expanding the concept of civic education to global society; adopts the ethical values of peace education and human rights education; draws upon the global society perspective provided by global education, which not only investigates global topics, but more specifically merges the global and the local into the glocal; combines mainly these three pedagogical fields through the concept of global citizenship in terms of political participation as such, but particularly on a global scale. (p. 4)

In this context, over the past 20 years, there has been increasing interest in GCE as a means of supporting learners in developing their values, knowledge, and understanding of multiple global, national, and local issues. Accordingly, a growing number of scholars have discussed and attempted to conceptualize critical (including postcolonial and environmental), transformative, cosmopolitan, humanistic, and value-creating positions of GCE (Bosio, 2021; Goulah, 2020; Guajardo \& Reiser, 2016; Pashby et al., 2020; Sharma, 2018, 2020).

Theoretically, we situate this article within an ethical position of GCE. By ethical GCE, we mean a reflexive pedagogical framework for GCE, in which global citizens are being created, at least indirectly and subtly, by means of the educational programs they access, while also creating their own social realities through interactions in multiple contexts and relationships in their professional and personal lives. In this view, the goal of promoting ethical values (e.g., justice, fairness, equity, respect, and integrity) and knowledge via GCE, as this article proposes, "implies not only reading the word, but also reading the world" (Goodman, 1992, p. 159) in ways that assist learners to formulate critical questions regarding the dominant forms of neoliberal globalization and its tenets of deregulation, privatization, and free trade. An ethical reflection process supports global citizens to develop comprehension of how they are morally implicated in the global economy, at least through their daily habits and choices as consumers, yet also hold meaningful elements of agency within global power structures. Ethical reflection can be empowering, allowing self-identifying global citizens to act and think outside their individual concerns, having had their consciousness raised with regard to the goal of modifying damaging social norms that have a negative impact on communities and the planet (Bosio \& Schattle, 2017; Schattle, 2021).

\section{Ethical global citizenship education}

From an ethical perspective, GCE places weight on specific personal capacities and qualities, such as self-awareness; international understanding; cross-cultural empathy; a sense of responsibility for the common good at home and beyond; a willingness to raise one's voice and take on active involvement to address key issues of shared global concern; and human values, such as empathy and solidarity directed toward humanity (Schattle, 2008; Young, 2008). This is a conceptualization of GCE in which educators make a specific commitment to learners' emancipation of the human spirit toward principles of global justice (Beitz, 2005). Ethical GCE is informed and inspired by the idea of a global ethic, a maximalist 
notion of rights, encompassing both negative and positive duties (e.g., duties to refrain from harming others as well as duties to protect and to assist others whose rights are subject to being violated). This requires an ontology that emphasizes how important it is for learners to change existentially, both in relation to the ways in which they exist in the world and the ways in which they interpret this world.

Ethical GCE integrates concepts of transformative learning that expand, for instance, upon Mezirow's (2000) concentration on deconstructing ingrained assumptions, focusing less on acquiring "knowledge for its own sake" and more intently on fostering a "global ethical consciousness" that moves the teaching and learning process toward a critically oriented reflexive pedagogy. As Cunliffe (2004) suggested, a critically oriented reflexive pedagogy

draws upon very different ways of thinking about the nature of reality as well as a different way of thinking about management learning. In particular, it means focusing on three issues:

Existential: Who am I and what kind of person do I want to be?

Relational: How do I relate to others and to the world around me?

Praxis: The need for self-conscious and ethical action based on a critical questioning of past actions and of future possibilities. (p. 408)

Global ethical consciousness development via ethical GCE can be considered through various dimensions (e.g., psychological, evolutionary, and sociological; Veugelers, 2011). Yet, GCE framed in an ethical perspective can also include political and cultural dimensions. McLaren (1994), as a critical educator, well described how we define an ethical GCE as both a sociopolitical practice and as part of the politics of social justice, locating the notion of values within an intrinsic/critical pedagogy perspective (not an instrumental/ market-driven one). The theories of Dewey $(1939,1944)$ distinguish between the means and the ends, usually defined as intrinsic values and instrumental values. Both concepts can be employed within GCE, especially in terms of the investigation into the ways in which GCE's goals can be developed and how they will influence the motivation of each individual. For example, one's choices and behavior patterns can be directed toward end goals (e.g., examination results and suitability for employment, rather than more holistic educational goals, such as deep learning and critical knowledge), generally in terms of neoliberal or market-oriented GCE. In the same way, market values based on how economically useful GCE can make students tend to point both instructional faculty and learners toward fulfilling end goals. This is exemplified in the notion of "learnification of education”, proposed by Biesta (2012).

The term learnification of education, as applied to our discussion in this article, signals a dynamic in which the language of learning makes it problematic to speak about the substantive purposes of GCE, and the role that a more ethically grounded GCE should play in forging a global common good beyond the economy of survival. This is the result of an emphasis on qualification in many of today's educational institutions (luckily not all of them) that often confines ethics to bundles of personal qualities and practices seen as advancing, if not ensuring, the success of graduates in the job market. Such market imperatives with regard to GCE have the effect of accentuating instrumental self-serving pedagogical approaches. This can have a significant impact on how engaged students are with learning and how much they self-identify as global consumers (rather than as global citizens). Therefore, we argue that educators with the aim of instilling in their students ethical 
perspectives within their respective fields should not think of the notion of global citizenship education as value neutral. There is a political/cultural dimension intersecting with pedagogy that educators must consider in toto if they are to enact GCE into the curriculum in ethical ways and foster the ethical global citizen. Thus, we argue that ethical GCE must focus on promoting strong links between the cognitive and the social development of global citizens (Waghid \& Davids, 2020).

We also believe that ethical GCE is about more than educational service delivery; rather, it should serve as a means of conscientization, as in achieving an in-depth and critical understanding of the world-allowing for the perception and exposure of social and political contradictions - and identity development through the transmission of knowledge, skills, and values across generations (Freire, 2018). This positions us, as educators, to be present and responsive in our teachings in an open way for welcoming and embracing the emergent global citizen. The implications of this are that ethical GCE must encourage global citizens to take responsibility for their way of being in the world and their participation in the process of creating meaning and action with others. Within this approach, global citizens understand the world as proceeding in an indefinite process of formation, cocreated on a continuing basis as a series of human interactions carried forward each day. In this way, knowledge is not static; rather, it is fluid and fostered through lively interactions among students and teachers. The term ethical focuses attention on all aspects of the learning/teaching environment as well as all aspects of the student experience, including five dimensions: values-creation, identity progression, collective involvement, glocal disposition, and an intergenerational mindset.

\section{Dimension 1: Values-creation}

Values-creation as a dimension of ethical GCE has its roots in the concept of soka (value-creating), which was proposed by the Japanese educator Tsunesaburo Makiguchi (1871-1944) and then advanced by his successors: Japanese Buddhist philosophers, authors, educators, and nuclear disarmament advocates Josei Toda (1900-1958) and Daisaku Ikeda. The value-creating dimension of ethical GCE is concerned with helping students perceive, acknowledge, and remove "the arrow of a discriminatory consciousness, an unreasoning emphasis on difference ... piercing the hearts of the people" (Ikeda, 1993, p. 2). Herewith there is an emphasis on the need to address stereotyping in the curriculum and to engender a capacity to extend compassion toward every person on earth; students should also be taught to recognize the types of power structures in today's increasingly globalized environment and the ways in which colonial attitudes (both in the former colonizers and former colonized societies) can continue to be perpetuated invisibly.

Thus, educational environments should be created that encourage genuine interactions across the lives of different kinds of people on the basis of wisdom (acknowledging that all human lives are interconnected), courage (looking deeply into one's heart and confronting one's own cowardice and arrogance), and compassion (being able to see beyond one's own immediate circumstances or cultural settings and empathize with the suffering of others) (Ikeda, 2010). In educational environments infused with wisdom, courage, and compassion, educators help students develop values such as empowerment, creativity, empathy, and a concern for humanity. This can be translated into a series of core principles that educators can help learners embrace in order to act as value-creators. These, according to Ikeda $(2010,2017)$, span the following: 
- Respect: a view of life that respects the sanctity of life and acknowledges the dignity of every human being

- Sense of mission: striving to realize a mission for the betterment of society, whatever it might be, by living with great compassion

- Protection: a pledge to protect humanity and live in ways that fulfil this vow

- Greater self: in this case, to live altruistically and to serve others, while establishing a "greater self"

- A multifaceted self: easily relate to others, along with the will to gain experience and learn throughout their lives, while providing the optimum solution to whatever situation might arise. (See also Bosio, 2020)

These principles can be incorporated within formal, non-formal, and informal education settings across a variety of different subjects and disciplines, and they potentially intersect with the identity progression dimension of ethical GCE discussed next.

\section{Dimension 2: Identity progression}

The dimension of identity progression in ethical GCE encompasses the development of personal capacities to be involved with and committed to principles that represent social responsibility in terms of thoughts, actions, and emotions. Learners who are going to be global citizens should be encouraged to make commitments to solving problems and resolving conflicts through negotiation and deliberation, while also becoming involved in public life-whether in local, national, or global arenas. Thinking about rights and duties not only in terms of one's hometown or home country but also when viewing the world as a single interconnected unit can give rise to a sense of global citizenship.

This can lead to problem solving in a variety of contexts, and one obvious context is the need today for a sense of global environmental citizenship (Jelin, 2010) to protect the planet and its ecosystems, reverse longstanding degradation of the environment, alleviate the threats of human-induced climate disruption and species extinction, and strengthen the capacity of the planet to sustain life for future generations (Hawken, 2017; McKibben, 2010, 2019). These ideals call upon global citizens to commit themselves to the kinds of beliefs and ethical standards outlined here and to lead their lives accordingly.

To help bring about one's identity progression as a global citizen, ethical GCE must begin by developing and strengthening the commitment of every global citizen to construct their personal lives in a way that enables them to live up to the ideals described above. Ideally, ethical GCE must not be seen as the province of a particular discipline, let alone civics classes or vague attempts to encourage "proper" behavior. Rather a purposeful approach to global citizenship — along with good citizenship, plain and simple — should be an integral part of the academic and extracurricular programs that make up university life, and it should be kept in mind as a priority by every faculty and staff member (Green, 2013). It must be recognized that universities cannot hope to accomplish these kinds of desired outcomes alone; the wider society, and particularly societal institutions that are important to students, need to provide additional resources for universities as they develop and implement ethical GCE. Likewise, the roles of universities in research advancement, knowledge dissemination, and community engagement can enrich the endeavors of civil society organizations that partner with educational institutions. 


\section{Dimension 3: Collective involvement}

Ethical GCE includes a collective element that acknowledges that while personal identity and personal commitments are important, action is also needed to advance these beliefs in society and politics. A global citizen should have the ability to join in public debates and strive to solve problems-once again, in multiple arenas, be they local, national, or global-in a manner that shows respect for people with different opinions, perspectives, and value systems. Being socially and politically involved is central to ethical GCE. Dealing with 21st-century challenges (e.g., nuclear proliferation, suicide terrorism, cyberattacks, public health crises, mass immigration, environmental devastation, and the global climate crisis) renders active citizen participation necessary in every sense.

Ethical GCE is not just about philosophy or ideology, as in belief systems that critique the world as it actually is and present alternative proposals or programs for the envisioned good society; it has to encompass substantive action. In this aspect, ethical GCE, as proposed in this study, transitions from approaches to citizenship education that demand the "good citizen" to a more globally oriented approach of caring about both the local and the global, referred to in this study as the glocal. Ethical GCE encourages global citizens to become active participants in the social and political life of their respective communities and countries. However, simple participation is not sufficient; action should not be undertaken for the sake of itself but in a useful and mindful fashion that fully respects the rights of others.

\section{Dimension 4: Glocal disposition}

An engaged global citizen is both a member and a participant situated within a number of different communities, some of which overlap: local communities, regional ones, national ones, and multinational ones. We refer to this multiplicity of spaces and to the kinds of sentiments and dispositions that accompany what it means to belong and fulfill responsibilities within them as glocal citizenship. This outlook, with implications for ethical GCE, grew out of research across the social sciences and humanities (e.g., Andreotti, 2011; Shultz, 2007) suggesting that, in recent generations, the world has become much more interdependent, and that this will continue as the current century progresses. Transformations in recent decades that have taken place in trade, immigration, communications, and technology have made it more feasible than ever to look at the planet and its people as part of an interconnected single unit.

The biggest issues and challenges of the 21 st century cannot be resolved by individual countries acting on their own and requires solutions that are not confined within the borders of any particular nation-state, even as the global citizen will always retain local, national, and cultural roots underpinning their senses of allegiance, belonging, and loyalty; this is what Kwame Anthony Appiah (1996) meant by the idea of "rooted cosmopolitanis", in which citizens_-or as he put it, "cosmopolitan patriots"-balance senses of belonging and moral obligation across communities both immediate and distant. A glocal disposition also calls upon individuals to fulfil Luis Cabrera's (2010) definition of a global citizen as one who works, whether within one's country or worldwide, to advance the human rights of individuals who do not happen to share their particular nation-state citizenship. 
With the staying power of nationality and national governments alongside globalization, the task at hand for ethical GCE is to connect the "patriotic national identity" of each citizen around the world with recognition of global interdependence and the many ways in which humanity and the planet share a common fate-a state of existence the late international relations theorist David Held (1999) aptly termed overlapping communities of fate.

\section{Dimension 5: Intergenerational mindset}

Facilitating an intergenerational mindset within ethical GCE calls upon global citizens, in facing the challenges of any given moment, to remember and take into account insights from the past as well as future obligations that span generations. Ethical GCE, in this view, seeks to acknowledge historical influences and help people cultivate an in-depth understanding of their own trajectories, as well as that of the world, so that they apply the lessons from the past when taking actions in the present. Moreover, while traditions and heritage shape any individual's personal understanding of citizenship, a global citizen must always be thinking about and be responsive to the impacts their present actions will likely have for future generations (Barry, 1997; Meyer, 2012; Tremmel, 2009). Ethical GCE requires that steps taken to overcome contemporary problems account for past and future contexts in order to avoid adopting inadequate short-term solutions. Our guiding philosophy and our resulting actions should always be informed by the widest of perspectives that combine a cosmopolitan outlook and political advocacy and also work across the realms of morality and culture (Oxley \& Morris, 2013).

\section{Implications of the framework and conclusion}

This article has focused on the components that might comprise an optimal framework for ethical GCE as both a method and a strategy at educational institutions at all levels. What we view as the principal five domains of ethical GCE have been outlined, these being values-creation, identity progression, collective involvement, glocal disposition, and an intergenerational mindset.

These five dimensions land (loosely) in three arenas: purpose (i.e., values-creation), relationships across self/others/communities (i.e., identity progression, collective involvement, glocal disposition), and historical (i.e., intergenerational mindset). For example, value creation is more concerned with developing the capacities of students to collaborate purposefully with and to take responsibility for their roles/duties within society, as well as their willingness and ability to create value in politics at local, national, and international levels. Identity progression, collective involvement, and glocal disposition are more concerned with fostering students' inclusive and expansive identity (or self), including individual participation in collective-sustainable action. By this we mean an ability to view and approach problems as a member of a glocal community, as well as a disposition to understand, accept, and tolerate cultural differences; the commitment to change one's lifestyle and consumption habits to protect the environment; the willingness to resolve conflict in a nonviolent manner; and the capacity to think in a critical and systemic way-for example, the ability to be sensitive across dividing lines of identity and culture and defend human 
rights (e.g., the rights of women, children, ethnic minorities) and deal with contemporary challenges (e.g., Covid-19).

At the same time, ethical GCE must foster global citizens who are not so exclusively preoccupied with the present that they lose sight of the past and the future (intergenerational mindset). In this regard, ethical GCE is essentially a reflexive pedagogical framework because it allows students to critically explore realms of thought and action that cross intellectual boundaries, ideas, and practices while supporting their ability to think and act within a comprehensive timeframe that embraces both past heritage(s) and the potential impacts of their actions on future generations. If discussed in this perspective, ethical GCE might also support students in feeling that they can be part of the creation of an alternative new future with its roots in social justice. It may become a "pedagogy of hope" (Freire, 1994) or a pedagogy of value (Bosio \& Waghid, 2021) through the application of which schools, universities, and educators may demonstrate they have not yet abandoned the lifeworld or become ignorant of political and moral questions.

Ethical GCE can therefore be conceptualized as a five-dimensional framework, as educators can implement an effective model of ethical GCE within their institutions by working toward fulfilling the five dimensions of values-creation, identity progression, collective involvement, glocal disposition, and an intergenerational mindset. Each dimension represents a major developmental pathway with certain attributes that teachers may implement into their GCE initiatives in order to develop value-creating, thoughtful, responsible, empathetic, and actively engaged global citizens (Figure 1).

To foster ethical global citizens, educators would do well to design programs that work across all five domains. This process need not follow a set order or linear trajectory; it can be understood as circular. For example, achieving learners' collective involvement might

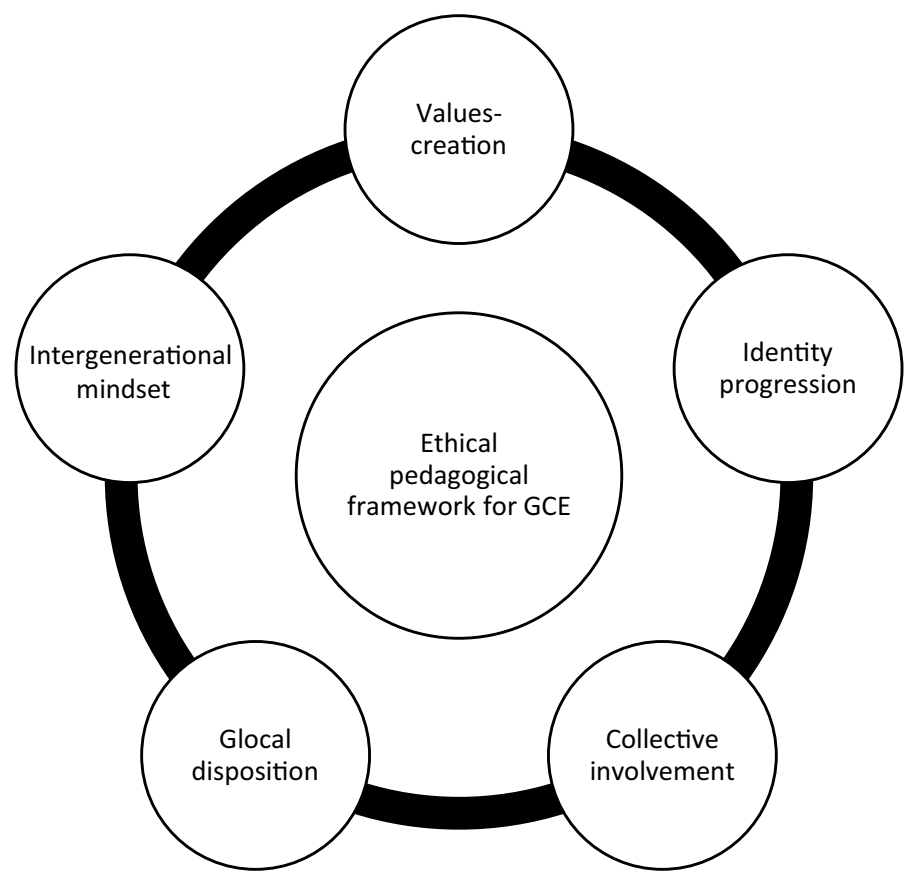

Figure 1. An ethical pedagogical framework for global citizenship education 
lead to an expansion in the boundaries of one's citizen identity at a later stage, or fostering a value-creating and intergenerational mindset may lead later-once again, in the life of the individual learner-to realizing a glocal disposition. Or the inverse of this progression can also emerge from endeavors of ethical GCE.

In any case, ethical CGE as an educational process needs to be grounded in notions of reciprocal respect and accountability. It must be infused with wisdom, courage, and compassion. Educators shall help students learn to recognize both the positive and negative moral obligations that accompany living as a human being at this moment in time-for example, by acknowledging the roles that developed nations, big corporations, and certain national leaders throughout history have played in creating systems of inequality, injustice, and oppression (Bosio \& Torres, 2019; Freire, 2018; Torres \& Bosio, 2020). Schools and universities can adapt this framework to their own specific contexts, purposes, and needs. Lastly, our proposed framework, by its very nature, is open to critical scrutiny. It can readily be revised and presented as a flexible analytical tool, ripe for further modification and refinement in relation to distinct educational contexts.

\section{References}

Andreotti, V. (2011). Actionable postcolonial theory in education. Berlin: Springer.

Appiah, K. A. (1996). Cosmopolitan patriots. In J. Cohen (Ed.), For love of country? Boston, MA: Beacon Press.

Barry, B. (1997). Sustainability and intergenerational justice. Theoria: A Journal of Social and Political Theory, 89, 43-64.

Beitz, C. R. (2005). Cosmopolitanism and global justice. In G. Brock \& D. Moellendorf (Eds.) Current debates in global justice (Vol 2, pp. 11-27). New York, NY: Springer. https://doi.org/10. 1007/1-4020-3847-X_2

Biesta, G. (2012). Philosophy of education for the public good: Five challenges and an agenda. Educational Philosophy and Theory, 44(6), 581-593.

Bosio, E. (2020). Towards an ethical global citizenship education curriculum framework in the modern university. In D. Bourn (Ed.), Bloomsbury handbook for global education and learning (pp. 187-206). London: Bloomsbury. https://doi.org/10.5040/9781350108769.0025

Bosio, E. (Ed.) (2021). Conversations on global citizenship education. London: Routledge.

Bosio, E., \& Schattle, H. (2017, October 12). Prof. Hans Schattle global citizenship education: Interview series with Dr. Emiliano Bosio [Video]. YouTube. https://youtu.be/Wg3EWF88vi8

Bosio, E., \& Torres, C. A. (2019). Global citizenship education: An educational theory of the common good? A conversation with Carlos Alberto Torres. Policy Futures in Education, 17(6), 745-760. https://doi.org/10.1177/1478210319825517.

Bosio, E., \& Waghid, Y. (Eds.) (2021). Global citizenship education in the Global South: Educators' perceptions and practices [Manuscript in preparation]. Leiden: Brill.

Cabrera, L. (2010). The practice of global citizenship. Cambridge: Cambridge University Press.

Cunliffe, A. L. (2004). On becoming a critically reflexive practitioner. Journal of Management Education, 28(4), 407-426. https://doi.org/10.1177/1052562904264440.

Dewey, J. (1939). Theory of valuation. Chicago: University of Chicago Press.

Dewey, J. (1944). Some questions about value. Journal of Philosophy, 41(17), 449-456.

Freire, P. (1994). Pedagogy of hope: Reliving pedagogy of the oppressed (R. R. Barr, Trans). New York, NY: Continuum.

Freire, P. (2018). Pedagogy of the oppressed. New York, NY: Bloomsbury.

Giroux, H. A., \& Bosio, E. (2021). Critical pedagogy and global citizenship education. In E. Bosio (Ed.), Conversations on global citizenship education: Perspectives on research, teaching, and learning in higher education (pp. 1-10). London: Routledge.

Goodman, J. (1992). Elementary schooling for critical democracy. New York: State University of New York Press.

Goulah, J. (2020). Daisaku Ikeda and the Soka movement for global citizenship. Asia Pacific Journal of Education, 40(1), 35-48. https://doi.org/10.1080/02188791.2020.1725432. 
Green, M. (2013). Acting as global citizens: A challenge to U.S. colleges and universities. International Education, November-December, 52-55.

Guajardo, M., \& Reiser, M. (2016). Humanism as the foundation for global citizenship education. Journal of Research in Curriculum and Instruction, 20(3), 241-252.

Hawken, P. (Ed.) (2017). Drawdown: The most comprehensive plan ever proposed to reverse global warming. London: Penguin.

Held, D. (1999). The changing contours of political community: Rethinking democracy in the context of globalisation. Theoria: A Journal of Social and Political Theory, 94, 30-47.

Ikeda, D. (1993). Mahayana Buddhism and twenty-first century civilization. http://www.daisakuikeda.org/ sub/resources/works/lect/lect-04.html

Ikeda, D. (2010). A new humanism: The university addresses of Daisaku Ikeda. New York, NY: I. B. Tauris.

Ikeda, D. (2017). The global solidarity of youth: Ushering in a new era of hope. https://www.sgi.org/aboutus/president-ikedas-proposals/peace-proposal-2017/index.html

Jelin, E. (2010). Towards a global environmental citizenship? Citizenship Studies, 4(1), 47-63.

McKibben, B. (2010). Eaarth: Making a life on a tough new planet. New York, NY: Times Books.

McKibben, B. (2019). Falter: Has the human game begun to play itself out? New York, NY: Henry Holt.

McLaren, P. (1994). Critical pedagogy, political agency, and the pragmatics of justice: The case of Lyotard. Educational Theory, 44, 319-340.

Meyer, L. H. (2012). Intergenerational justice. London: Routledge.

Oxley, L., \& Morris, P. (2013). Global citizenship: a typology for distinguishing its multiple conceptions. British Journal of Educational Studies, 61(3), 301-225.

Pashby, K., da Costa, M., Stein, S., \& Andreotti, V. (2020). A meta-review of typologies of global citizenship education. Comparative Education, 56(2), 144-164. https://doi.org/10.1080/03050068.2020. 1723352.

Sharma, N. (2018). Value-creating global citizenship education: Engaging Gandhi, Makiguchi, and Ikeda as examples. London: Palgrave Macmillan.

Sharma, N. (2020). Integrating Asian perspectives within the UNESCO-led discourse and practice of global citizenship education: Taking Gandhi and Ikeda as examples. In D. Bourn (Ed.), Bloomsbury handbook for global education and learning (pp. 90-102). New York, NY: Bloomsbury Academic.

Schattle, H. (2008). The practices of global citizenship. Lanham, MD: Rowman and Littlefield.

Schattle, H. (2021). Global citizenship education as awareness, responsibility and participation. In E. Bosio (Ed.), Conversations on global citizenship education: perspectives on research, teaching, and learning in higher education (pp. 153-169). London: Routledge.

Shultz, L. (2007). Educating for global citizenship: Conflicting agendas and understandings. Alberta Journal of Educational Research, 53(3), 248.

Torres, C. A., \& Bosio, E. (2020). Global citizenship education at the crossroads: Globalization, global commons, common good, and critical consciousness. Prospects, 48, 99-113. https://doi.org/10.1007/ s11125-019-09458-w.

Tremmel, J. C. (2009). A theory of intergenerational justice. London: Routledge.

Waghid, Y., \& Davids, N. (2020). Teachers matter: Educational philosophy and authentic learning. Lanham: Lexington Books.

Veugelers, W. (2011). The moral and the political in global citizenship: Appreciating differences in education. Globalisation, Societies and Education, 9, 473-485. https://doi.org/10.1080/14767724.2011. 605329.

Wintersteiner, W., Grobbauer, H., Diendorfer, G., \& Reitmair-Juárez, S. (2015, November 2). Global citizenship education. Citizenship education for globalizing societies. https://www.peace-ed-campaign. org/global-citizenship-education-citizenship-education-for-globalizing-societies/

Young, M. (2008). From constructivism to realism in the sociology of the curriculum. Review of Research in Education, 32(1), 1-28. https://doi.org/10.3102/0091732x07308969.

Publisher's Note Springer Nature remains neutral with regard to jurisdictional claims in published maps and institutional affiliations.

Emiliano Bosio is an educator, author, and public intellectual. Currently, Professor Bosio teaches at Toyo University in Japan. He is the editor of Conversations on Global Citizenship Education (Routledge) and a research committee member at the Center for Global Nonkilling (CGNK) in the United States. Professor Bosio is also a contributor to the Academic Network on Global Education and Learning (ANGEL), a UKbased network established in close cooperation between the Global Education Network of Europe (GENE) 
and the Development Education Research Center (DERC) at the University College London Institute of Education.

Hans Schattle is professor of political science at Yonsei University in Seoul, South Korea. He works across the usual dividing lines in political science and international relations, with interests ranging from globalization, citizenship, media, and democracy to the politics of Europe and East Asia. Professor Schattle has written two books (The Practices of Global Citizenship and Globalization and Citizenship, both published by Rowman and Littlefield), as well as numerous articles in academic journals. He earned his doctorate in politics at Oxford, and most recently, he has coedited the volume Making Social Democrats: Citizens, Mindsets, Realities, published by Manchester University Press. 